\title{
PERCEPATAN MENGHAFAL AL-QUR'AN MELALUI PEMBELAJARAN KOSA KATA BAHASA ARAB
}

\author{
Amirul Mukminin \\ Universitas Ibrahimy Situbondo \\ mora.mukmin@gmail.com
}

\begin{abstract}
:
Basically, the general obstacle or problem in memorizing al-Qur'an in Indonesia is about the language of the Qur'an which is a foreign language for memorizers in Indonesia. Which is the language of the Tahfidz al-Qur'an is the latest innovation in MTs SA ALHIDAYAH Batu-Malang City. To applicate this program was greatly helped by the existence of Arabic learning that had taken place before the Tahfidz program. So that, with the collaboration of learning Arabic and tahfidz, students feel helped and fast in memorizing. The one of methods used in learning Arabic that help with the tahfidz program is Arabic vocabulary memorization system and its meanings as much as possible.
\end{abstract}

Keywords: learning Arabic, Tahfidz Program

\section{PENDAHULUAN}

Al-Qur'an adalah kalam Allah Swt. yang diturunkan kepada Nabi Muhammad Saw. Bagi yang membacanya adalah suatu ibadah dan mendapat pahala. Al-Qur'an disampaikan melalui malaikat Jibril yang terpercaya kepada Nabi Muhammad. MAlQur'an berfungsi sebagai pedoman hidup bagi umat manusia, menjadi ibadah bagi yang membacanya, serta pedoman dan sumber petunjuk dalam kehidupan. ${ }^{1}$

Al-Qur'an merupakan wahyu Allah yang paling agung dan bacaan mulia serta dapat dituntut kebenaranya oleh siapa saja, sekalipun akan menghadapi tantangan kemajuan ilmu pengetahuan yang semakin canggih, al-Qur'an diturunkan dalam bahasa Arab, sehingga bahasa Arab menjadi bahasa kesatuan umat Islam sedunia, sehingga menimbulkan persatuan yang dapat dilihat pada waktu sholat jamaah dan ibadah haji, selain dari pada itu bahasa Arab tidak berubah. Jadi sangat mudah diketahui bila alQur'an hendak ditambah atau dikurangi. ${ }^{2} \mathrm{Al}-$ Qur'an merupakan kitab yang terakhir diturunkan, namun al-Qur'an menjadi kunci

\footnotetext{
${ }^{1}$ Muhammad Mas'ud, Quantum Bilngan-bilangan A $l$ Qur'an (Yogyakarta: Diva Press, 2008), 69.

${ }^{2}$ Inu Kencana Syafiie, Pengantar Filsafat (Bandung: PT. Refika Adi Tama, 2004), 102.
}

dan kesimpulan dari semua kitab suci yang pernah diturunkan kepada nabi-nabi dan rasul-rasul yang diutus Allah sebelum Nabi Muhammad. Allah Swt telah memerintahkan agar menjaga al-Qur'an dari perubahan dan pergantian. Hal ini tidak terjadi dalam kitab suci yang telah diturunkan sebelumnya.

Hafalan al-Qur'an apabila dinisbatkan kepada Allah Swt. Adalah menjaga kemurnian, perubahan, penyimpangan, dan penambahan dan pengurangan. Sedangkan kalau dinisbatkan kepada makhluk, maksudnya adalah menalarnya, mengamalkan ketentuan-ketentuannya, dan disibukkan olehnya baik itu merenungkan, mengajarkan, mempelajarinya. Dalam pengertian seperti inilah yang dimaksud oleh Rasulullah Saw. Melalui ungkapannya yang artinya: Ya Allah saya mohon kepada-Mu hendaknya hatiku dapat menghafal al-Qur'an. ${ }^{3}$

Pada zaman sekarang ini kegiatan kaum muslimin untuk menghafalkan ayatayat al-Qur'an, baik itu secara keseluruhan ataupun sebagian semakin meningkat. Indonesia merupakan negara yang penduduknya mayoritas muslim terbesar di dunia, namun ironisnya kenyataan di lapangan

\footnotetext{
3 Bambang Saiful Ma'arif, Teknik Menghafal AlQur'an (Bandung: Sinar Baru Algensindo, 2005), 27.
} 
menunjukkan bahwa jumlah umat Islam di Indonesia yang hafal al-Qur'an tidak sebanding jika dibandingkan dengan jumlah komunitas muslim di dalamnya, terlebih pada zaman pemuda pemudi sekarang yang cenderung ketergantungan pada alat-alat komunikasi, apabila di kalkulasikan secara matematik jumlah hafiz al-Qur'an (orang yang hafal al-Qur'an) di Negara Indonesia belum mencapai $1 \%$ dari seluruh komunitasnya. ${ }^{4}$ Menghafal al-Qur'an merupakan suatu keutamaan yag besar, dan posisi itu selalu didambakan oleh semua orang, dan seorang yang bercita-cita tulus, serta berharap pada kenikmatan duniawi dan ukhrawi agar manusia nanti menjadi warga Allah dan dihormati dengan penghormatan yang sempurna. ${ }^{5}$ Jika ingin membuat pemuda pemudi mencintai al-Qur'an, maka jadikanlah rumah anda sebagai rumah yang patut dijadikan teladan dan contoh yang baik, bagi orang yang akan berinteraksi dengan alQur'an, dimana di dalam rumah ini harus ada penghormatan yang sungguh-sungguh kepada al-Qur'an. ${ }^{6}$ Di dalam ajaran Islam para penghafal ini lebih diutamakan dari pada yang lainya dalam hal memberi fatwa, pendapat, serta, dalam sebuah pandangan.

Setiap orang memiliki cara atau metode sendiri untuk mempermudah dan memperlancar dalam menghafal al-Qur'an. namun demikian, yang paling banyak digunakan adalah yang cocok, sesuai dan menyenangkan bagi setiap individu. Jika diteliti, kebanyakan yang cocok bagi setiap orang diperoleh melalui beberapa kali percobaan.

Pada zaman sekarang ini kegiatan kaum muslimin untuk menghafalkan ayatayat al-Qur'an, baik itu secara keseluruhan ataupun sebagian semakin meningkat. Hal ini benar adanya, karena banyaknya lembaga pendidikan Islam yang memasukkan kurikulum Tahfidz al-Qur'an dalam lembaga tersebut. Dalam menghafal al-Qur'an tidak

\footnotetext{
${ }^{4}$ Mahbub Junaidi, Menghafal Al-Qur'an Itu Mudah (Solo CV.Angkasa Solo, 2006), 13.

5 Sa'dulloh, 9 Cara Praktis Menghafal Al-Qur'an (Jakarta: Gema Insani, 2008), 23.

${ }^{6}$ Sa'ad Riyadh, Agar Anak Mencintai Dan Hafal AlQur'an (Bandug: Irsyad Baitus Salam, 2007), 21
}

boleh asal-asalan, tapi ada beberapa syarat yang harus dipenuhi. Salah satu syarat yang harus dipenuhi oleh seseorang yang ingin menghafal al-Qur'an adalah ia harus sudah mampu membaca al-Qur'an dengan fasih dan sesuai dengan kaidah ilmu tajwidnya. Hukum membaca al-Qur'an sesuai dengan ilmu tajwid adalah wajib, karena apabila membaca al-Qur'an tidak sesuai dengan kaidah tajwid akan dapat merubah makna yang terkandung di dalam ayat tersebut.

Pada dasarnya kendala atau problematika secara umum dalam menghafal al-Qur'an di Indonesia ialah mengenai bahasa al-Qur'an yang merupakan bahasa asing bagi para penghafal di Indonesia. Bahasa merupakan salah satu media untuk menyampaikan maksud dan tujuan seseorang kepada lainnya. Gagasan atau pikiran dapat tersampaikan dengan jelas melalui bahasa. Setiap bangsa memiliki bahasa masingmasing, bahkan satu bangsa bisa memiliki lebih dari satu bahasa. Setiap bahasa juga memiliki keunikan dan keistimewaan tersendiri. Salah satu contohnya adalah bahasa Arab, yaitu bahasa yang digunakan oleh masyarakat bangsa Arab. Ia memiliki keistimewaan sebagai bahasa al-Qur'an, kitab suci umat muslim.

Dari keistimewaan itu, bahasa Arab menjadi salah satu bahasa yang dipelajari oleh banyak orang. Tidak hanya di negerinya saja tetapi hampir di seluruh penjuru dunia. Bahkan bahasa Arab saat ini sudah merupakan bahasa Internasional dimana banyak literatur yang menggunakan bahasa Arab.

Bahasa Arab termasuk bahasa asing yang menempati posisi penting di Indonesia, khususnya umat Islam, sebab bahasa Arab adalah bahasa al-Qur'an dan Hadist, yang keduanya adalah fondasi agama Islam. Bahasa Arab juga merupakan bahasa kebudayaan Islam dan bergbagai disiplin ilmu seperti filsafat, ilmu kalam, ilmu hadist, tafsir, dan sebagainya.

Bahasa Arab telah lama berkembang di Indonesia, akan tetapi tampaknya mempelajari bahasa Arab sampai saat ini 
tidak luput dari problem. ${ }^{7}$ Fenomena yang berkembang di masyarakat menunjukkan bahwa belajar bahasa Arab masih dianggap sulit dan rumit, karena itu banyak kalangan masyarakat yang kurang tertarik untuk mempelajarinya, padahal setiap bahasa memiliki tingkat kesulitan dan kemudahan yang berbeda-beda tergantung karakteristik sistem bahasa itu sendiri.

Dari uraian tersebut, tergambar dengan jelas betapa urgennya untuk mempelajari bahasa Arab terhadap proses menghafal al-Qur'an. Maka tidak berlebihan jika bahasa Arab perlu mendapat penekanan dan perhatian seksama, mulai dari tingkat Taman Kanak-Kanak sampai pada lembaga pendidikan tinggi, baik negeri ataupun swasta, umum maupun agama. Hal ini tentu disesuaikan dengan taraf kemampuan dan perkembangan anak didik.

Madrasah Tsanawiyah Satu Atap (MTs SA) ALHIDAYAH Kota Batu-Malang, merupakan salah satu lembaga tingkat menengah yang aktivitas menghafal al-Qur'an termasuk dalam pembelajaran yang diterapkan pada ekstrakulikuler pendukung atau pelajaran muatan lokal, namun penerapannya dilakukan pada saat jam sekolah. Sedangkan, pelajaran bahasa Arab di MTs SA ALHIDAYAH Kota Batu-Malang ini merupakan pelajaran wajib yang masuk dalam kegiatan belajar siswa.

Sebagaimana telah dijelaskan di atas, bahwa al-Qur'an sumber rujukan umat Islam berbahasa arab, sehingga untuk mempelajarinya, terlebih dahulu harus mempelajari bahasa Arab. Begitu eratnya antara al-Qur'an dan bahasa Arab sehingga sering digambarkan bahwa keduanya bagaikan dua sisi keping uang logam yang tak dapat dipisah satu sama lain.

Dalam pembelajaran al-Qur'an tidak bisa lepas dengan pembelajaran bahasa Arab, baik dari aspek kosa kata, gramatikal, dan kandungannya. Sehingga dalam pembelajarannya harus saling menunjang antara satu dengan lainnya, sebagaimana yang

\footnotetext{
${ }^{7}$ Muna WA, Metodologi Pembelajaran Bahasa Arab Teori dan Aplikasi (Yogyakarata: SUKSES Offset, 2011), 1 .
}

telah terlakasana di MTs SA ALHIDAYAH Kota Batu-Malang.

Penelitian ini bertujuan untuk menggambarkan, mengkaji, dan menganalisis percepatan menghafal al-Qur'an dengan adanya pembelajaran bahasa Arab. Oleh karena itu, permasalahan yang diangkat dalam penelitian adalah bagaimana percepatan menghafal al-Qur'an dengan adanya pembelajaran bahasa Arab di MTs SA ALHIDAYAH Kota Batu-Malang?

\section{METODE PENELITIAN}

Pendekatan penelitian yang dipakai merupakan pendekatan penelitian kualitatif, peneliti berkeinginan untuk memahami makna-makna dibalik fenomena yang terjadi secara alamiah di lapangan dan menganalisisnya. Dan teknik pengumpulan data menggunakan observasi partisipatif dan deep interview.

\section{TEMUAN PENELITIAN DAN PEMBAHASAN}

Tahfidz Al-Qur'an adalah salah satu program terobosan terbaru yang ada di MTs SA ALHIDAYAH Kota Batu-Malang. Selain menyalurkan minat para siswa, program tahfidz memberikan manfaat yang sangat besar dikarenakan tujuan utamanya mengajarkan membaca al-Qur'an dengan baik sesuai dengan tajwidnya, mencintai serta menyenangi al-Qur'an baik membaca bahkan menghfalnya.

Bahasa yang dipakai dalam al-Qur'an merupakan bahasa Arab, yang mana bahasa Arab merupakan salah satu bahasa yang dipelajari oleh banyak orang. Tidak hanya di negerinya saja tetapi hampir di seluruh penjuru dunia. Bahkan bahasa Arab saat ini merupakan bahasa Internasional di mana banyak literatur yang menggunakan bahasa Arab.

Pembelajaran Bahasa Arab di MTs SA ALHIDAYAH Kota Batu-Malang ialah menggunakan beberapa metode, salah satunya adalah dengan menghafalkan kosakata bahasa arab. Dengan menggunakan metode tersebut, para peserta pondok tahfidz yang ada di MTs SA ALHIDAYAH Kota Batu-Malang sangatlah terbantu dalam hal percepatan 
menghafalkan al-Qur'an. Hal itu disebabkan oleh beberapa faktor:

1. Tugas wajib menghafal mufrodat Guru bahasa Arab memberikan lima kosa kata Arab di setiap jam pelajaran bahasa Arab yang harus dihafal oleh siswa. Dengan begitu siswa yang mengikuti program tahfidz akan mulai terbiasa menghafal kosa kata Arab yang membantu kepada aktivitas menghafal alQur'an yang memang menggunakan bahasa Arab juga di MTs SA ALHIDAYAH Kota Batu-Malang.

2. Guru melatih siswa dalam pelafalan mufrodat yang akan dihafal

Pembelajaran bahasa Arab yang diajarkan di sekolah khususnya pada pelafalan dan penghafalan mufrodat atau kosa kata sangat menekankan tiga cara pelafalan, yaitu:

- مخارج الحروف adalah tempat keluarnya huruf, guru Bahasa Arab sangat memperhatikan cara siswa di dalam pelafalan huruf Arab pada mufrodat yang diajarkan.

- adalah penekanan dan intonasi siswa di dalam pelafalan mufrodat, hal itu sangatlah berpengaruh kepada makna yang dimaksud dari masing-masing mufrodat yang dirangkai menjadi satu kalimat tersebut.

- صفات الحروف adalah sifat yang dimiliki dari masing-masing huruf seperti halnya huruf صuruf ini adalah salah satu huruf الاستعلاء menurut bahasa berarti naik atau terangkat, maksudnya adalah ketika mengucapkan huruf lidah terangkat/naik ke langit-langit mulut. ${ }^{8}$

3. Kesamaan cara menghafal mufrodat

Cara menghafal mufrodat yang diajarkan di sekolah mempunyai kesamaan dengan cara menghafal yang diajarkan pada program tahfidz itu sendiri yaitu dengan

\footnotetext{
${ }^{8}$ M. Basori Alwi Murtadho, Mabadi' Ilmu Tajwid, (Malang, CV. Rahmita, 2009, cet., 29), h. 13
}

mengetahui arti dari mufrodat yang dihafal. Seperti kolom di bawah ini:

- Mufrodat atau kosa kata yang dihafal dalam al-Qur'an

\begin{tabular}{|c|c|c|c|}
\hline اليل & 9 & الضحى & 9 \\
\hline Malam & Dan & $\begin{array}{l}\text { Waktu } \\
\text { Dhuha }\end{array}$ & Dan \\
\hline اذا & سجى & ما & ودعكك \\
\hline $\begin{array}{c}\text { Apabil } \\
\text { a }\end{array}$ & $\begin{array}{l}\text { Telah } \\
\text { Sunyi }\end{array}$ & Tidak & $\begin{array}{c}\text { Meninggalka } \\
\mathrm{nmu}\end{array}$ \\
\hline ربك & وما & قلى & وللاخرة \\
\hline $\begin{array}{c}\text { Tuhan } \\
\text { mu }\end{array}$ & $\begin{array}{l}\text { Dan } \\
\text { Tidak }\end{array}$ & $\begin{array}{c}\text { Benci/Ma } \\
\text { rah }\end{array}$ & $\begin{array}{l}\text { Kehidupan } \\
\text { Akhirat }\end{array}$ \\
\hline خير & للك & من & الاولى \\
\hline $\begin{array}{c}\text { Lebih } \\
\text { Baik }\end{array}$ & $\begin{array}{l}\text { Bagi } \\
\text { mu }\end{array}$ & Daripada & $\begin{array}{l}\text { Kehidupan } \\
\text { Dunia }\end{array}$ \\
\hline
\end{tabular}

- Mufrodat atau kosa kata yang dihafal dalam buku belajar bahasa arab siswa

\begin{tabular}{|c|c|c|c|}
\hline دَفْقَرْ & 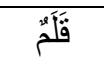 & مِنْطَرَةُ & سَبَُوْرَرَةٌ \\
\hline Buku & Pena & Penggaris & Papan tulis \\
\hline مِمْسَحَةُّة & كُرْنسيُّ & مَكَكْنَبْ & 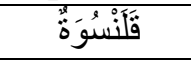 \\
\hline Penghapus & Kursi & Meja & Songkok \\
\hline عَرَقُقُ & ظَفْرْر & صَذْرِ & دَدْمُ \\
\hline Keringat & Kuku & Dada & Darah \\
\hline حَجِبٌُ & ذَفَقَنْ & ذِرَاعَ & كَفة \\
\hline Alis & Dagu & Lengan & $\begin{array}{l}\text { Telapak } \\
\text { Tangan }\end{array}$ \\
\hline
\end{tabular}

Dengan dibiasakannya siswa melafalkan huruf Arab dan menghafal kosa kata Arab dengan menerapkan ketiga aspek penting di atas menjadikan siswa MTs SA ALHIDAYAH Kota Batu-Malang yang mengikuti program Tahfidz merasa terbantu dengan kesingkronan ilmu bahasa Arab yang diperoleh di sekolah dengan kegiatan menghafal al-Qur'an di lembaga tersebut.

\section{SIMPULAN}

Pembelajaran Bahasa Arab di MTs SA ALHIDAYAH Kota Batu-Malang adalah menggunakan beberapa metode, salah satunya adalah dengan menghafalkan kosakata bahasa arab beserta artinya sebanyak mungkin, sambil lalu dirangkai menjadi kalimat singkat yang biasa dipakai sehari-hari. Dengan menggunakan metode tersebut, para siswa yang mengikuti program tahfidz di lembaga tesebut sangat terbantu dalam hal percepatan 
menghafalkan al-Qur'an. Hal itu disebabkan karena dengan hafalan kosakata beserta artinya tersebut, membuat peserta program tahfidz mulai terbiasa melafalkan bahasa Arab yang notabeninya adalah bukan bahasa para peserta sehari-hari dan merupakan bahasa yang dipakai dalam al-Qur'an dengan pelafalan yang baik dan benar.

\section{DAFTAR PUSTAKA}

Muhammad Mas'ud, 2008, Quantum Bilngan-bilangan A l-Qur'an, Yogyakarta, Diva Press.

Inu Kencana Syafiie, 2004, Pengantar Filsafat, Bandung, PT. Refika Adi Tama.

Bambang Saiful Ma'arif, 2005, Teknik Menghafal Al-Qur'an, Bandung, Sinar Baru Algensindo.

Mahbub Junaidi, 2006, Menghafal Al-Qur'an Itu Mudah, Solo, CV.Angkasa Solo.

Sa'dulloh, 2008, 9 Cara Praktis Menghafal Al-Qur'an, Jakarta, Gema Insani.

Sa'ad Riyadh, 2007, Agar Anak Mencintai Dan Hafal Al-Qur'an, Bandug, Irsyad Baitus Salam.

Muna WA, 2011, Metodologi Pembelajaran Bahasa Arab Teori dan Aplikasi, Yogyakarata, SUKSES Offset.

M. Basori Alwi Murtadho, 2009, cet., 29, Mabadi' Ilmu Tajwid, Malang, CV. Rahmita. 